\title{
Large enteroviral vaccination studies to prevent type 1 diabetes should be well founded and rely on scientific evidence. Reply to Skog 0, Klingel K, Roivainen M et al [letter]
}

\author{
Jessica L. Dunne ${ }^{1}$ (D) Sarah J. Richardson ${ }^{2} \cdot$ Mark A. Atkinson $^{3} \cdot$ Maria E. Craig $^{4} \cdot$ Knut Dahl-Jørgensen $^{5,6}$. \\ Malin Flodström-Tullberg ${ }^{7}$ - Heikki Hyöty ${ }^{8,9} \cdot$ Richard E. Lloyd $^{10} \cdot$ Noel G. Morgan $^{2}$ - Alberto Pugliese ${ }^{11,12,13}$
}

Received: 4 March 2019 / Accepted: 20 March 2019 / Published online: 23 April 2019

(C) Springer-Verlag GmbH Germany, part of Springer Nature 2019

Keywords Antiviral agents $\cdot$ Clinical trials $\cdot \mathrm{DiViD} \cdot$ Enterovirus $\cdot$ Islet $\cdot \mathrm{nPOD}$

\section{Abbreviations \\ PKR Protein kinase R \\ VP1 Viral protein 1}

To the Editor: We are pleased that Skog et al [1] have accepted the challenge to respond to our recent 'For Debate' article [2]. In this, we proposed that both vaccination and trials with antiviral therapies are warranted, based on decades of studies implicating an association between enterovirus infections and type 1 diabetes. It is pleasing to observe these conclusions were similarly supported by Skog et al [1].

However, while supporting our overall conclusions, the authors also challenged several pieces of evidence cited in our article, and we believe it important to respond to each challenge. First, Skog et al question the value of antiviral therapies at clinical onset of type 1 diabetes because they contend that the evidence for viral infection post diagnosis is weak [1]. In response, we would cite the growing evidence for: (1) chronic autoimmunity and persistent insulin secretion extending for many years after diagnosis [3-5]; (2) the existence of beta cell dysfunction at onset (reviewed in $[6,7]) ;(3)$ the negative impact of viral infections on beta cell function $[8$, 9]; and (4) the increasing evidence (some of which is unpublished) supporting pancreatic viral infections near diagnosis and several years thereafter [10]. Furthermore, enterovirus nucleic acids/proteins in human samples (including blood) have been associated with type 1 diabetes in several meta-
Jessica L. Dunne

JDunne@JDRF.org

Sarah J. Richardson

S.Richardson@exeter.ac.uk

JDRF, 26 Broadway, 14th Floor, New York, NY 10004, USA

2 Institute of Biomedical and Clinical Science, University of Exeter Medical School, RILD Building, Barrack Road, Exeter EX2 5DW, UK

3 Departments of Pathology and Pediatrics, College of Medicine, University of Florida, Gainesville, FL, USA

4 School of Women's and Children's Health, Faculty of Medicine, University of New South Wales, Sydney, NSW, Australia

5 Department of Pediatric and Adolescent Medicine, Oslo University Hospital, Oslo, Norway

6 Institute of Clinical Medicine, Faculty of Medicine, University of Oslo, Oslo, Norway
Center for Infectious Medicine, Department of Medicine Huddinge, Karolinska Institutet, Karolinska University Hospital, Stockholm, Sweden

8 Faculty of Medicine and Life Sciences, University of Tampere, Tampere, Finland

9 Fimlab Laboratories, Pirkanmaa Hospital District, Tampere, Finland

10 Department of Molecular Virology and Microbiology, Baylor College of Medicine, Houston, TX, USA

11 Diabetes Research Institute, Miller School of Medicine, University of Miami, Miami, FL, USA

12 Department of Medicine, Division of Endocrinology, Diabetes and Metabolism, Miller School of Medicine, University of Miami, Miami, FL, USA

13 Department of Microbiology and Immunology, Miller School of Medicine, University of Miami, Miami, FL, USA 
analyses $[11,12]$. We believe the best way to resolve this issue is to undertake a randomised controlled trial using antiviral agents at diagnosis; one such trial, led from Oslo, Norway, is already recruiting across Scandinavia. Of course, one factor that may influence the outcome is the fact that the efficacy of antiviral agents against persistent enteroviral infections is largely unknown and this must be borne in mind when evaluating the results. Nevertheless, even a modest effect would provide supportive evidence for the continued pursuit of antiviral strategies.

In our article [2], we did not discuss in detail how vaccination trials for type 1 diabetes prevention might be designed, but we are happy to clarify here that, in the first phase, relevant target groups might include those with increased genetic risk for type 1 diabetes, populations with very high disease incidence, and children acquiring multiple autoantibodies by 3 years of age as a surrogate for disease progression. We agree that enteroviral vaccines should target multiple strains, and we would not expect that all cases of type 1 diabetes would be prevented, given the possible role of other viruses or that some individuals may develop disease in the absence of viral infections.

Clearly, our key conclusion that the weight of evidence favours the hypothesis that enteroviruses are associated with type 1 diabetes [2] is not based solely on reports claiming to have isolated viruses from the pancreas. We accept that these are few and that in one study [13] the isolate may have resulted from laboratory contamination, as we have emphasised previously [14]. Nevertheless, in our view, Skog et al [1] have overstated the problem of contamination; especially in relation to the Diabetes Virus Detection Study (DiViD). In that work, contamination is extremely unlikely as an explanation for the source of enterovirus because: (1) the biopsy collections were performed under sterile conditions in the operating room; (2) enterovirus RNA was amplified from islet supernatants, but could not be amplified from the equivalent cultures of pancreatic exocrine cells; and (3) enterovirus sequences differed among the participants. We agree, however, that studies that compare the viral RNA sequences detected in tissue and supernatants are needed, and these too are ongoing.

Skog et al [1] have also proposed that 'any evidence for an association between enterovirus and type 1 diabetes based on IHC [immunohistochemistry] with the Dako VP1 [viral protein 1] antibody should be disregarded'. This is a singular claim given that the fidelity of this antibody has been tested rigorously under the stringent conditions we use [15]. In addition, and as they suggested, we have also tested additional antibodies and find that the majority are much less sensitive than the Dako anti-VP1 reagent [16]. However, as noted in one earlier study [17], some additional antisera do label equivalent islet cells to those stained by the Dako clone in pancreas sections from people with type 1 diabetes. Skog et al [1] also drew attention to the poor correlation between VP1 immunopositivity in pancreas sections and the ability to amplify enteroviral sequences by PCR. Unlike Skog and colleagues, we expect that a perfect correlation will be difficult to achieve if one considers that the two assays (detection of immunoreactive VP1 and PCR amplification of viral nucleic acid sequences) are performed on paraffin and frozen tissues, respectively, and that there can be significant variability in the detection of viral signals when adjacent tissue blocks are examined. Indeed, anecdotally, we have found such discrepancies in our own studies but these have been resolved when further regions of the tissue are analysed.

In terms of protein kinase R (PKR) staining, Skog and colleagues $[1,18]$ argue that PKR is expressed uniformly in all cells of the pancreas. We contend that this is incorrect. PKR is certainly present in the islet at low levels (this point has never been in dispute) but its level varies dramatically between those cells that stain positively for enterovirus VP1 compared with those that do not. This is true both in control individuals (where the number of such cells is very low) and in people with type 1 diabetes (where more islet cells stain positively) $[10,14]$. These observations are firmly consistent with the activation of an antiviral response involving upregulation of PKR in a small subset of islet cells [14]. We agree that selectively detecting the phosphorylated form of PKR would also be desirable, but we have not been able to find suitable antisera to label this form reliably in fixed tissue samples. We assume from their recent paper that Skog and colleagues [1, $18]$ have also failed in this objective, although we note that they did not analyse virally infected samples in their study. In support of the proposal that PKR activation follows from viral infection in islet cells, we have demonstrated that the labile anti-apoptotic protein myeloid cell leukaemia sequence-1 (Mcl-1) is selectively lost from islet cells in which PKR expression is increased, a response that is entirely consistent with the activation of translational arrest induced by active PKR [10].

We acknowledge that our article [2] cited information from ongoing (currently unpublished) studies, in which novel approaches have been employed including, for example, the application of proteomics to pancreas extracts as a means to identify the sequence of the enterovirus VP1 peptide recognised by the Dako antibody (J. Nyalwidhe and J. Nadler, Eastern Virginia Medical School, Norfolk, VA, USA, personal communication). We felt it important to include such emerging information as representative of the current state-of-the-art.

In closing, we stand by our conclusion, with which Skog et al [1] seem to agree, that there is sufficient evidence deriving from multiple studies using a wide range of approaches to implicate enteroviruses in type 1 diabetes. At the same time, we agree that many questions remain and that scientists must work collegially to address these outstanding issues. However, we also suggest that a point has been reached where 
vaccination trials represent the most effective means to resolve the debate once and for all. In support of this, we drew attention to the fact that one company has weighed the evidence independently and has reached the conclusion that investment in the development of a polyvalent enteroviral vaccine represents a sound scientific and commercial venture [19]. We expect that the outcome of such vaccination studies will establish or disprove a role for enteroviruses in type 1 diabetes. Supporting this notion, we are interested to note the very recent publication of an Australian study reporting a decreased incidence of type 1 diabetes following the introduction of a rotavirus vaccine [20]. The authors cite previous evidence associating rotavirus infections with type 1 diabetes $[20,21]$ and the possibility should not be overlooked that co-infection with rotavirus and other viruses (including different enterovirus types) might contribute to the development of type 1 diabetes.

Funding Work in the authors' laboratories is supported by the SouthEastern Norway Regional Health Authority (grant to K.D.-J.), the Novo Nordisk Foundation (grants to KD-J and MF-T), the Swedish Child Diabetes Foundation (grant to MF-T), the Swedish Research Council (grant to MF-T), and by the PEVNET (Persistent Virus Infection in Diabetes Network) Study Group funded by the European Union's Seventh Framework Programme (FP7/2007-2013) under grant agreement number 261441 PEVNET. Some of the authors (AP, SJR, NGM, HH, MAA, REL and MF-T) are supported by JDRF 3-SRA-2017-492-A-N, which funds the nPOD Virus Group in collaborative studies of virus infections in the pancreas with type 1 diabetes. Studies in the Exeter laboratory were supported by a JDRF-CDA award (5-CDA-2014-221A-N to SJR), and by grant support from MRC (MR/P010695/1) and Diabetes UK (15/0005364) to SJR and NGM. MEC is supported by an Australian National Health and Medical Research Council (NHMRC) Practitioner fellowship [APP1045777]

Duality of interest $\mathrm{HH}$ is a shareholder and member of the Board of Vactech Ltd., which develops picornavirus vaccines. HH and MF-T serve on the scientific advisory board of Provention Bio Inc., which is developing an enterovirus vaccine.

Contribution statement All authors were responsible for drafting the article and revising it critically for important intellectual content. All authors approved the version to be published.

\section{References}

1. Skog O, Klingel K, Roivainen M, Korsgren O (2019) Large enteroviral vaccination studies to prevent type 1 diabetes should be well founded and rely on scientific evidence. Diabetologia. https://doi. org/10.1007/s00125-019-4841-1

2. Dunne JL, Richardson SJ, Atkinson MA et al (2019) Rationale for enteroviral vaccination and antiviral therapies in human type $1 \mathrm{di}-$ abetes. Diabetologia 62(5):744-753. https://doi.org/10.1007/ s00125-019-4811-7
3. Campbell-Thompson M, Fu A, Kaddis JS et al (2016) Insulitis and beta-cell mass in the natural history of type 1 diabetes. Diabetes 65(3):719-731. https://doi.org/10.2337/db15-0779

4. Wasserfall C, Nick HS, Campbell-Thompson M et al (2017) Persistence of pancreatic insulin mRNA expression and proinsulin protein in type 1 diabetes pancreata. Cell Metab 26(3):568-575. https://doi.org/10.1016/j.cmet.2017.08.013

5. Oram RA, Jones AG, Besser RE et al (2014) The majority of patients with long-duration type 1 diabetes are insulin microsecretors and have functioning beta cells. Diabetologia 57(1):187-191. https://doi.org/10.1007/s00125-013-3067-x

6. Sun J, Cui J, He Q, Chen Z, Arvan P, Liu M (2015) Proinsulin misfolding and endoplasmic reticulum stress during the development and progression of diabetes. Mol Asp Med 42:105-118. https://doi.org/10.1016/j.mam.2015.01.001

7. Brozzi F, Eizirik DL (2016) ER stress and the decline and fall of pancreatic beta cells in type 1 diabetes. Ups J Med Sci 121(2):133139. https://doi.org/10.3109/03009734.2015.1135217

8. Gallagher GR, Brehm MA, Finberg RW et al (2015) Viral infection of engrafted human islets leads to diabetes. Diabetes 64(4):1358 1369. https://doi.org/10.2337/db14-1020

9. Petzold A, Solimena M, Knoch KP (2015) Mechanisms of beta cell dysfunction associated with viral infection. Curr Diab Rep 15(10): 73. https://doi.org/10.1007/s11892-015-0654-x

10. Richardson SJ, Leete P, Bone AJ, Foulis AK, Morgan NG (2013) Expression of the enteroviral capsid protein VP1 in the islet cells of patients with type 1 diabetes is associated with induction of protein kinase $\mathrm{R}$ and downregulation of Mcl-1. Diabetologia 56(1):185-193. https://doi.org/10.1007/ s00125-012-2745-4

11. Allen DW, Kim KW, Rawlinson WD, Craig ME (2018) Maternal virus infections in pregnancy and type 1 diabetes in their offspring: Systematic review and meta-analysis of observational studies. Rev Med Virol 28(3):e1974. https://doi.org/10.1002/rmv.1974

12. Yeung WC, Rawlinson WD, Craig ME (2011) Enterovirus infection and type 1 diabetes mellitus: systematic review and metaanalysis of observational molecular studies. BMJ 342:d35. https:// doi.org/10.1136/bmj.d35

13. Dotta F, Censini S, van Halteren AG et al (2007) Coxsackie B4 virus infection of beta cells and natural killer cell insulitis in recentonset type 1 diabetic patients. ProcNatlAcadSciUSA 104(12): 5115-5120. https://doi.org/10.1073/pnas.0700442104

14. Morgan NG, Richardson SJ (2014) Enteroviruses as causative agents in type 1 diabetes: loose ends or lost cause? Trends Endocrinol Metab 25(12):611-619. https://doi.org/10.1016/j. tem.2014.08.002

15. Richardson SJ, Leete P, Dhayal S et al (2014) Evaluation of the fidelity of immunolabelling obtained with clone 5D8/1, a monoclonal antibody directed against the enteroviral capsid protein, VP1, in human pancreas. Diabetologia 57(2):392-401. https://doi.org/10. 1007/s00125-013-3094-7

16. Laiho JE, Oikarinen M, Richardson SJ et al (2016) Relative sensitivity of immunohistochemistry, multiple reaction monitoring mass spectrometry, in situ hybridization and PCR to detect Coxsackievirus B1 in A549 cells. J Clin Virol 77:21-28. https:// doi.org/10.1016/j.jcv.2016.01.015

17. Richardson SJ, Willcox A, Bone AJ, Foulis AK, Morgan NG (2009) The prevalence of enteroviral capsid protein vp1 immunostaining in pancreatic islets in human type 1 diabetes. Diabetologia 52(6):1143-1151. https://doi.org/10.1007/s00125-009-1276-0

18. Jonsson A, Yngve E, Karlsson M, Ingvast S, Skog O, Korsgren O (2019) Protein kinase R is constitutively expressed in the human 
pancreas. J Histochem Cytochem 67(2):99-105. https://doi.org/10. 1369/0022155418802838

19. Proventionbio (2017) Provention Bio, Inc. Announces clinical program focus on intercepting and preventing the onset of type 1 diabetes. Available from http://investors.proventionbio.com/2017-0718-Provention-Bio-Inc-Announces-Clinical-Program-Focused-onIntercepting-and-Preventing-the-Onset-of-Type-1-Diabetes. Accessed 26 March 2019

20. Perrett KP, Jachno K, Nolan TM, Harrison LC (2019) Association of rotavirus vaccination with the incidence of type 1 diabetes in children. JAMA Pediatr 173(3):280-282. https://doi.org/10.1001/ jamapediatrics.2018.4578

21. Honeyman MC, Coulson BS, Stone NL et al (2000) Association between rotavirus infection and pancreatic islet autoimmunity in children at risk of developing type 1 diabetes. Diabetes 49(8): 1319-1324. https://doi.org/10.2337/diabetes.49.8.1319

Publisher's note Springer Nature remains neutral with regard to jurisdictional claims in published maps and institutional affiliations. 